\title{
Patient with Eisenmenger's Syndrome and Severe Progressive Kyphoscoliosis Presents for Posterior Spinal Fusion
}

\author{
Christopher F. Tirotta, MD, MBA ${ }^{1 *}$,Alecia L. S. Stein, MD, MS², and Richard G. Lagueruela, MD² \\ ${ }^{\prime}$ Director Cardiac Anesthesia, The Heart Program of Nicklaus Children's Hospital, The Heart Program \\ ${ }^{2}$ Nicklaus Children's Hospital, The Heart Program, USA
}

\begin{abstract}
"Corresponding author: Dr. Christopher F. Tirotta, MD, MBA, Director Citation: Tirotta CF, Stein ALS, Lagueruela RG (2017) Patient with Cardiac Anesthesia, The Heart Program, Nicklaus Children's Hospital, Eisenmenger's Syndrome and Severe Progressive Kyphoscoliosis Presents for 3100 SW 62nd Avenue,Miami, FL 33155, USA, Tel: 305-663-8456; Fax: Posterior Spinal Fusion. Enliven: J Anesthesiol Crit Care Med 4(1): 001. 305-663-8573;E-mail: christirotta@att.net

Received Date: $09^{\text {th }}$ December 2016

Accepted Date: $12^{\text {th }}$ January 2017

Published Date: $18^{\text {th }}$ January 2017

Copyright: @ 2017 Dr. Christopher F. Tirotta. This is an Open Access article published and distributed under the terms of the Creative Commons Attribution License, which permits unrestricted use, distribution and reproduction in any medium, provided the original author and source are credited.
\end{abstract}

\begin{abstract}
A fourteen year old male patient with Eisenmenger's syndrome (ES) and severe, progressive kyphoscoliosis presented for posterior spinal fusion, T2-L2. A thorough, preoperative evaluation and multidisciplinary conference was completed to discuss patient management and the very high risk nature of this procedure. The patient underwent the procedure, but decompensated with reduction of the spinal curvature, which we believe produced right ventricular compression leading to an irreversible pulmonary, hypertensive crisis. The patient expired later the same day.
\end{abstract}

Keywords: Eisenmenger's syndrome; Congenital heart disease; Non-cardiac surgery; Kyphoscoliosis; Spine surgery

\section{Abbreviations}

ES: Eisenmenger's Syndrome; TGA: Transposition Great Arteries; VSD: Ventricular Septal Defect; ASD: Atrial Septal Defect; SVC: Superior Vena Cava; ASO: Arterial Switch Operation; PVOD: Pulmonary Vascular Occlusive Disease; RV: Right Ventricular; PA: Pulmonary Artery; $\mathrm{SPO}_{2}$ : Pulse Oximeter Saturation; HGB: Hemoglobin; HCT: Hematocrit; NIBP: Non-Invasive Blood Pressure; HR: Heart Rate; ECG: Electrocardiogram; NIRS: Near Infrared Spectroscopy; IV: Intravenous; IJ: Internal Jugular; CVL: Central Venous Line; CVP: Central Venous Pressure; SSEP: Somatosensory Evoked Potentials; ABG: Arterial Blood Gas; BE: Base Excess; $\mathrm{FIO}_{2}$ :Inspired oxygen concentration; NO: Nitric Oxide; PPM: Parts Per Million; $\mathrm{ETCO}_{2}$ : End-Tidal Carbon Dioxide; PBF: Pulmonary Blood Flow; CICU: Cardiac Intensive Care Unit; SVR: Systemic Vascular Resistance; PVR: Pulmonary Vascular Resistance

\section{Introduction}

Children with ES face the need for anesthesia for non-cardiac surgery in increasing numbers. There are some, but not extensive, guidelines, case reports and outcome data [1-3]. Most cases discussed are classified as low/ moderate risk, emergent or obstetrical; not high risk elective surgery as will be described below [4-9]. This case report presents a case of a multi-level spinal fusion for progressive, severe kyphoscoliosis in the setting of suprasystemic pulmonary arterial pressure due to ES.

\section{Case Report}

A fourteen-year-old, $35.5 \mathrm{~kg}$ patient with ES presented for surgery for posterior spinal fusion from T2 to L2 due to severe kyphoscoliosis. Past history included d-transposition of the great arteries (d-TGA), conoventricular ventricular septal defect (VSD), ostium secundum atrial septal defect (ASD) and left superior vena cava (SVC). An arterial switch operation (ASO) was performed at age nine; the patient had already developed pulmonary vascular occlusive disease (PVOD) and Eisenmenger physiology due to the open ASD and VSD. After a multidisciplinary meeting, including orthopedic surgery, cardiology, cardiac anesthesia, and cardiac intensive care, to discuss the risks, benefits and peri-operative management, the decision was made to proceed, despite the very high risk of peri-operative morbidity and mortality. Surface echocardiogram showed moderate residual ASD and VSD with bidirectional flow, no obstruction to flow from the ASO, elevated right ventricular (RV) and pulmonary artery (PA) pressures. There was mildly depressed biventricular function.

During preoperative consultation and optimization the noteworthy findings were pulse oximetry saturation $\left(\mathrm{SpO}_{2}\right)$ of $91 \%$, hemoglobin (HGB)$15.7 \mathrm{gm} / \mathrm{dL}$, hematocrit (HCT)-45.3\%. Non-invasive blood pressure (NIBP) was 100/65, and heart rate (HR) was 83 beats per minute (bpm). Preoperative medications included gabapentin and bosentan. Chest $\mathrm{x}$-ray demonstrated "post-surgical chest" with pulmonary vascular congestion and kyphoscoliosis. 
The patient was pre-medicated with $3 \mathrm{mg}$ midazolam. Standard monitors, like electrocardiogram (ECG), NIBP, $\mathrm{SpO}_{2}$, capnography and cerebral and somatic near infrared spectroscopy (NIRS), were employed. General intravenous (IV) anesthesia was uneventfully induced with etomidate $12 \mathrm{mg}$ and rocuronium $70 \mathrm{mg}$. Another peripheral IV was placed, along with an arterial line, and a right internal jugular (RIJ) central venous line (CVL). Initial central venous pressure (CVP) was $10 \mathrm{~mm} \mathrm{Hg}$. Somatosensory evoked potentials (SSEP) were also used. Maintenance of anesthesia was with remifentanil, $0.05 \mathrm{mcg} / \mathrm{kg} / \mathrm{min}$, dexmedetomidine, $0.5 \mathrm{mcg} / \mathrm{kg} / \mathrm{hr}$, and low dose sevoflurane, less than $0.5 \%$. The patient was then positioned in the prone position. Vasopresin, $0.0001 \mathrm{units} / \mathrm{kg} / \mathrm{min}$, was started prophylactically to avoid hypotension. Initial arterial blood gas (ABG) prior to incision, breathing $100 \%$ oxygen, was $\mathrm{pH}-7.31, \mathrm{pCO}_{2}-47.8 \mathrm{~mm} \mathrm{Hg}, \mathrm{pO}_{2}-213 \mathrm{~mm}$ $\mathrm{Hg}, \mathrm{HCO}_{3}-24.1 \mathrm{mEq} / \mathrm{L}$, Base Excess (BE)- -3. Saturation-100\%, HBG-15 g/ $\mathrm{dL}, \mathrm{HCT}-44$, lactate- $1.49 \mathrm{mg} / \mathrm{dL}$. The patient was maintained on an inspired oxygen concentration $\left(\mathrm{FiO}_{2}\right)$ of $100 \%$ throughout the case. Nitric oxide (NO) was also started prophylactically at 20 parts per million (PPM).

About two hours after surgical incision and temporally related to reduction of the spinal curvature, the patient experienced decreases in $\mathrm{SpO}_{2}$ from $100 \%$ to the low $90 \mathrm{~s}$ and high $80 \mathrm{~s}$. Heart rate also increased from $80-90 \mathrm{bpm}$ to 110-130 bpm and end tidal carbon dioxide $\left(\mathrm{ETCO}_{2}\right)$ decreased to $20-25 \mathrm{~mm}$ $\mathrm{Hg}$. CVP also increased to $15 \mathrm{~mm} \mathrm{Hg}$. ABG done at this time showed $\mathrm{pH}-$ 7.27, $\mathrm{pCO}_{2}-44.5, \mathrm{pO}_{2}-75, \mathrm{HCO}_{3}-20.4$, BE- (-6), Saturation-93, HBG-12.6, HCT-37. NO was increased to 40 PPM. 40 meq of sodium bicarbonate was administered. The surgeon was notified of this change in hemodynamics and the surgeon promptly released the distraction. Unfortunately, the patient's hemodynamics continued its downward trend despite hyperventilation, NO, vasopressin, and epinephrine at $0.05 \mathrm{mcg} / \mathrm{kg} / \mathrm{min}$. It was presumed the patient was suffering from a pulmonary hypertensive crisis.

Despite the surgical release, the patient did not improve. Subsequent ABG showed $\mathrm{pH}-7.303, \mathrm{pCO}_{2}-40.3, \mathrm{pO}_{2}-46, \mathrm{HCO}_{3}-20$, BE- -6, Saturation-77, lactate-1.28. The patient was given 350 cc packed red blood cells (RBC), inotropic support was increased, and hyperventilation was maintained. Despite improvements in blood pressure, the patient remained profoundly cyanotic with little evidence of pulmonary blood flow (PBF). $\mathrm{ETCO}_{2}$ remained less than $10 \mathrm{~mm} \mathrm{Hg}$. Surgical closure was completed and the patient was transferred to the Cardiac Intensive Care Unit (CICU) in very critical condition. Despite maximal pulmonary vasodilator therapy, the patient expired later that day.

\section{Discussion}

Anesthetic goals for patients with ES include the avoidance of triggering pulmonary vasoconstriction and a pulmonary hypertensive crisis. This is done by maintaining systemic vascular resistance (SVR) and reducing pulmonary vascular resistance (PVR) to promote left to right shunt flow. An important part of this strategy is to avoid hypotension while ensuring adequate anesthesia/analgesia. Our case was uneventful using a combination of dexmedetomidine, remifentanil, low dose sevoflurane and prophylactic vasopressin and NO to achieve these goals. The use of a dexmedetomidine/ketamine combination has been previously reported[9]. Things were progressing smoothly until saturations and $\mathrm{ETCO}_{2}$ started a precipitous downward trend upon reduction of the spinal curvature. These changes progressed rapidly, despite the reversal of the spinal reduction, to what we believe ultimately was an unbreakable pulmonary hypertensive crisis, followed by cardiopulmonary collapse, despite initiation of maximal pulmonary vasodilator therapy and support.

Although successful outcomes have been reported in a host of surgical procedures in patients with ES [3-8], we could find no literature describing surgical correction of severe kyphoscoliosis in such a patient who survived. The series reported by Amash et al., included one patient for "spinal fusion" for scoliosis who died on the $10^{\text {th }}$ post-operative day after a complicated postoperative course. Of the 24 reported surgical cases in this series, this patient had "the longest anesthesia time $(525 \mathrm{~min})$, the lowest intraoperative systemic pressure $(78 \mathrm{~mm} \mathrm{Hg})$, necessitating the largest fluid resuscitation needed $(6,475 \mathrm{cc})$ and ultimately needing inotropic and mechanical ventilation support for 24 hours following her surgery"[3]. Bennett et al. described a series of 53 anesthetic cases in patients with ES, but none included major spine surgery[4]. Khan et al. described one patient undergoing a T5T7 laminectomy for epidural abscess who decompensated during the case, but was successfully resuscitated and survived [10].

In the average scoliotic patient, it is not uncommon to see transient perturbations in pulmonary function when the abnormal curvature is reduced [11]. We postulate reduction of the spinal curvature in this patient triggered an irreversible pulmonary hypertensive crisis ultimately leading to death. We hypothesize his prior median sternotomy resulted in scarring that adhered the right ventricle to the sternum, rendering the cardiac chambers vulnerable to conformational changes with reduction of the spinal curvature. This resulted in a compressed RV with spinal reduction, greatly diminishing pulmonary blood flow and precipitating the hemodynamic decline. This phenomenon has been reported previously by echocardiography in a patient without structural heart disease, but with pectus excavatum during spinal fusion in the prone position [12]. We also offer as evidence an echocardiogram (Figure 1) from a different patient with a complete atrioventricular canal (CAVC), and severe scoliosis, undergoing cardiac surgery; this is the pre-repair, post anesthetic induction transesophageal echocardiogram. This picture clearly demonstrates compression of the RV cavity, even in the supine position and without reduction of the spinal curvature.

Spinal fusion has been reported to be one of the orthopedic procedures with the highest incidence of adverse outcomes [13,14]. Combine this with the severe physiological disturbances associated with ES and there is a very high probability of serious morbidity or mortality.We would recommend that patients with ES not undergo elective spinal fusion for severe kyphoscoliosis.

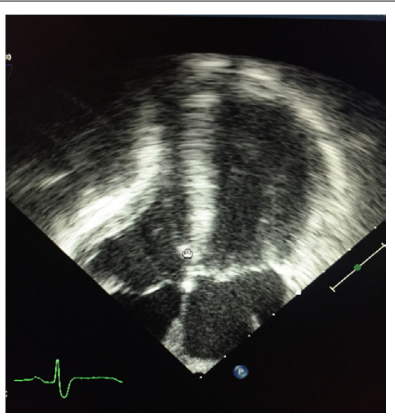

Figure 1: Intraoperative pre-repair transesophageal echocardiogram from a patient with severe scoliosis and undergoing repair of CAVC. 


\section{References}

1. Daliento L, Somerville J, Presbitero P, Menti L, Brach-Prever S, et al. (1998) Eisenmenger syndrome. Factors relating to deterioration and death. Eur Heart J 19: 1845-1855.

2. Das $\mathrm{BB}(2010)$ Perioperative care of children with Eisenmenger syndrome undergoing non-cardiac surgery. PediatrCardiol36: 11201128.

3. Ammash NM, Connolly HM, Abel MD, Warnes CA(1999) Noncardiac surgery in Eisenmenger syndrome. J Am CollCardiol 33: 222-227.

4. Bennett JM, Ehrenfeld JM, Markham L, Eagle SS (2014) Anesthetic management and outcomes for patients with pulmonary hypertension and intracardiac shunts and Eisenmenger syndrome: a review of institutional experience. J ClinAnesth 26: 286-293.

5. Solanki S, Vaishnav V, Vijay A (2010) Non-cardiac surgery in a patient with Eisenmenger syndrome - anaesthesiologist's challenge. J AnaesthesiolClinPharmacol 26: 539-540.

6. Fang G, Tian Y, Mei W (2011) Anaesthesia management of caesarean section in two patients with Eisenmenger's syndrome. Anesthesiol Res Pract 2011: 972671.

7. Gurumurthy T, Hegde R, Mohandes B (2012)Anaesthesia for a patient with Eisenmeger's syndrome undergoing caesarean section. Indian JAnaesth 56: 291-294.

8. Puri GD, Pradhan A, Kumar B, Hegde HV, Singh A, et al. (2011) Anaesthetic management of a patient with Eisenmenger's syndrome for lower abdominal surgery. Trends in Anaesth Critical Care 1: 51-53.
9. Goyal R, Singh S, Bangi A, Singh SK (2013) Case series: Dexmedetomidine and ketamine for anesthesia in patients with uncorrected congenital cyanotic heart disease presenting for non-cardiac surgery. J AnaesthesiolClinPharmacol29: 543-546.

10. Khan ZH, Zeinaloo AA, Khan RH, Rasouli MR (2009) Cardiac decompensation in a patient with Eisenmenger Syndrome undergoing T5-T7 levels laminectomy in the sitting position. Turk Neurosurg 19: 86-90.

11. Wazeka AN, DiMaio MF, Boachie-Adjei O (2004) Outcome of pediatric patients with severe restrictive lung disease following reconstructive spine surgery. Spine 29: 528-535.

12. Galas JM, van der Velde ME, Chiravuri SD, Farley F, Parra D, et al. (2009) Echocardiographic diagnosis of right ventricular inflow compression associated with pectus excavatum during spinal fusion in prone position. Congenit Heart Dis 4: 193-195.

13. Basques B, Lukasiewicz A, Samuel A, Webb ML, Bohl DD, et al. (2015) Which pediatric orthopaedic procedures have the greatest risk of adverse outcomes? J PediatrOrthop 1-6.

14. Basques B, Chung S, Lukasiewicz A, Webb ML, Samuel AM, et al. (2015) Predicting short-term morbidity in patients undergoing posterior spinal fusion for neuromuscular scoliosis. Spine 40: 1910-1917.

Submit your manuscript a http://enlivenarchive.org/submit-manuscript.php New initiative of Enliven Archive

Apart from providing HTML, PDF versions; we also provide video version and deposit the videos in about 15 freely accessible social network sites that promote videos which in turn will aid in rapid circulation of articles published with us. 